\title{
Conformación de póntico E en sector anterior.
}

\author{
Pontic E conformation at anterior sector.
}

Miguel Ángel Padilla Hernández,* Gabriela Hernández Gómez, ${ }^{\ddagger}$
Jaime Alejandro Nieto Ramírez, ${ }^{\ddagger}$ Trilce Melannie Virgilio Virgilio

RESUMEN

El póntico E es una alternativa de tratamiento para la pérdida prematura dental, este tipo de póntico fue publicado por primera vez en 2014 por Robert P. Korman. El diseño del póntico permite ofrecer predictibilidad en cuanto a soporte y mantenimiento de la arquitectura gingival, también promueve que el tejido vestibular migre coronalmente sobre el póntico, creando un surco gingival. Se recibió a una paciente que presentaba fragmento radicular del diente 21 y ausencia del diente 12, reborde residual atrófico (clase I según Seibert). Como plan de tratamiento, se realizó la extracción atraumática del fragmento radicular del diente 21 para retardar el colapso del reborde alveolar y se colocó injerto de tejido conectivo en la zona del diente 12 para corregir el defecto clase I de Seibert, se realizó la conformación de los nichos gingivales con electrobisturí en conjunto con la prótesis provisional y la preparación de los dientes pilares para la recepción y rehabilitación con pónticos E. Se colocó una prótesis fija de cinco unidades (dientes 13 al 23) en material núcleo de $\mathrm{Zr}$ y estratificada con cerámica.

Palabras clave: Póntico E, reborde residual, estética.

\section{ABSTRACT}

Pontic $E$ is an alternative treatment for premature dental loss, this type of pontic was published for the first time in 2014 by Robert P. Korman. The design of the pontic allows to offer predictability in terms of support and maintenance of the gingival architecture, it also promotes that the vestibular tissue migrates coronally over the pontic, creating a gingival groove. A patient was received who presented a radicular fragment of tooth 21 and absence of tooth 12, atrophic residual ridge (class I according to Seibert). As a treatment plan, atraumatic extraction of the root fragment of tooth 21 was performed to delay the collapse of the alveolar ridge and connective tissue graft was placed in the area of tooth 12 to correct Seibert's class I defect, conformation was performed of the gingival niches with electrocautery in conjunction with the provisional prosthesis and the preparation of the abutment teeth for the reception and rehabilitation with pontics E. A fixed prosthesis of five units was placed (teeth from 13 to 23) of $\mathrm{Zr}$ core material and stratified with ceramic.

Keywords: E pontic, alveolar edge, esthetic.

\section{INTRODUCCIÓN}

E xiste un gran número de pacientes que sufren pérdidas dentales prematuras, las cuales están relacionadas con diversas causas como graves problemas periodontales, trauma por accidentes, alteraciones del

\footnotetext{
* Licenciado en Odontología.

₹ Especialista en Periodoncia e Implantología. Profesor adscrito en el área de Periodoncia.

§ Especialista en Prótesis Bucal e Implantología. Profesora Ordinaria de Carrera Asociada B tiempo completo. Responsable del Área de Prótesis y Rehabilitación Funcional y Estética.
}

Escuela Nacional de Estudios Superiores (ENES) Unidad León. Universidad Nacional Autónoma de México (UNAM). León, Guanajuato, México.

Recibido: 20 Agosto 2019.

Aceptado para publicación: 11 Febrero 2020. desarrollo, etcétera. Con base en dichos padecimientos dentales, se han propuesto distintas soluciones protésicas cuyo objetivo es el remplazo de los dientes perdidos, devolviendo estética y función al paciente. Uno de estos procedimientos son los pónticos, que desde hace tiempo se han utilizado como un tratamiento para rebordes residuales. Un póntico es un diente artificial en una prótesis fija que reemplaza un diente natural perdido, restaura su función y usualmente abarca el espacio previamente ocupado por la corona clínica. ${ }^{1-6}$ El póntico E tiene un diseño innovador, el tejido gingival palatino no cubre el póntico, los ángulos del póntico son rectos $\left(90^{\circ}\right)$ y la superficie del póntico que se encuentra en contacto con el nicho gingival es plana, es considerado como una buena opción terapéutica estética y funcional para sustituir las ausencias dentales y brindar una buena conformación gingival. Su diseño permite tener un buen mantenimiento de la papila y del tejido gingival circundante. La forma 
anatómica del póntico cumple con los requisitos para mantener la salud periodontal y ofrece predictibilidad de resultados estéticos y funcionales a largo plazo. El póntico debe ir sumergido de 2 a $3 \mathrm{~mm}$ en la encía, debe existir un espacio interproximal entre pilar y póntico de $2 \mathrm{~mm}$. Debe existir el suficiente tejido blando sobre el reborde alveolar para poder hacer este tipo de conformaciones gingivales. ${ }^{7}$ El objetivo del caso clínico que se presenta a continuación fue brindar armonía dentogingival y un adecuado perfil de emergencia a través de la aplicación de la técnica de conformación de póntico $\mathrm{E}$ en un paciente femenino de 42 años, que presentaba fragmento radicular del diente 21 y reborde residual atrófico en la zona del diente 12, donde se empleó técnica de conformación de pónticos en E.?

\section{PRESENTACIÓN DEL CASO}

Mujer de 42 años de edad, sin ningún compromiso sistémico, que acude a la clínica de profundización al

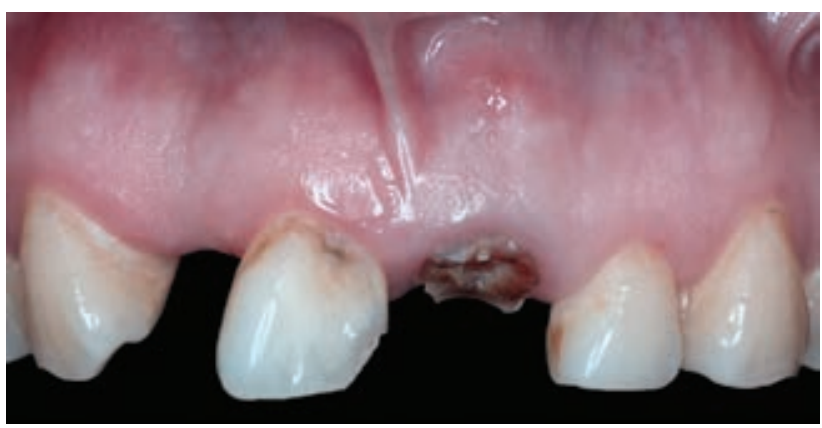

Figura 1: Fotografía clínica anterosuperior.

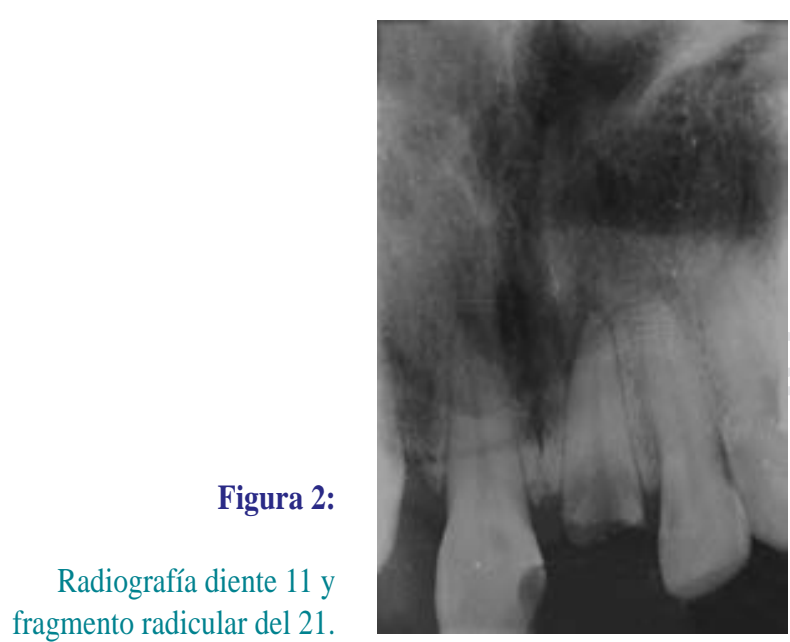

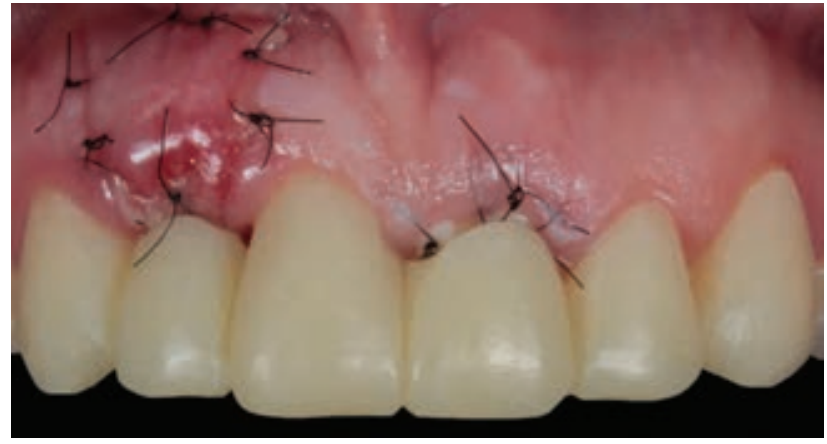

Figura 3: Semana 1 postquirúrgico, con prótesis provisional.

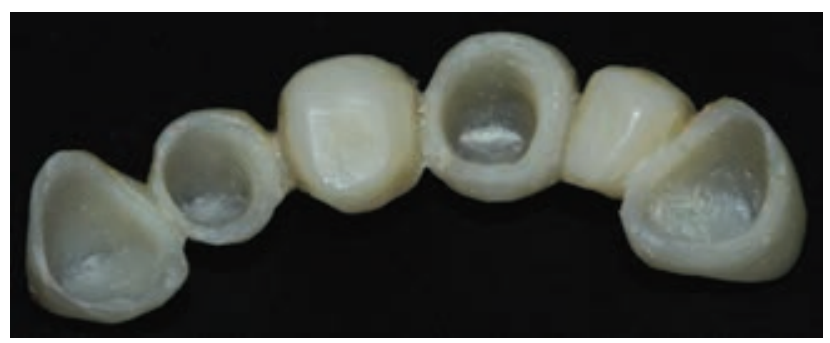

Figura 4: Prótesis provisional con los pónticos E confeccionados.

área de rehabilitación funcional y estética en la ENES Unidad León, UNAM. A la exploración clínica se observó la ausencia de los dientes 47, 36 y 12 . Paciente refiere traumatismo y avulsión del diente 12 hace tres años. En la zona del diente 12 presentaba reborde residual atrófico, que se clasificó como clase I Seibert (defecto del reborde alveolar, representado en pérdida del tejido vestíbulo-palatino). El fragmento radicular del diente 21, restauraciones con amalgama en los dientes 46 y 16 , además de una lesión cariosa en el diente 11. El diagnóstico protésico fue: paciente parcialmente edéntulo con colapso del reborde residual clase I de Seibert en el segmento anterior (Figura 1). ${ }^{8-13}$

En el análisis radiográfico se observa una lesión periapical en el fragmento radicular del 21 y también se observa la pérdida de tejido dental en el diente 11 por la lesión cariosa y la ausencia del diente 12 (Figura 2). Se procedió a realizar el tratamiento de conductos del diente 11 y se realizó interconsulta con el área de periodoncia para realizar la extracción atraumática del 21 y el injerto de TC en la zona del diente 12 para corregir defecto.

Se realizó la preparación protésica de los dientes pilares $(13,11,22$ y 23) para iniciar con la fase quirúrgica y de prótesis provisionales. Se procedió con la extracción 
atraumática y preservación del alveolo realizado con hidroxiapatita y el injerto de tejido conectivo en la zona del diente 12 , junto con la colocación de la prótesis provisional realizada con acrílico autocurable para cementar la prótesis provisional, se evitó cualquier contacto entre el acrílico y los tejidos blandos para no intervenir en el proceso de cicatrización, se citó a control a la paciente a los siete días después de la cirugía (Figura 3).

Los puntos de sutura se removieron a la segunda semana; después de cinco semanas de la cirugía, los tejidos se encontraron totalmente cicatrizados y estables. Se obtuvo una impresión de la arcada superior con polivinilsiloxano (HydroXtreme, Coltene), se realizó el diseño del póntico de acuerdo al artículo publicado por Robert P. Korman y siguiendo las especificaciones antes descritas sobre la modificación en el modelo maestro para confeccionar la prótesis provisional con pónticos E (ángulos rectos, superficie plana), que serviría para la conformación de los nichos gingivales en la paciente. Las prótesis provisionales fueron hechas con acrílico autocurable y caracterizadores (Figura 4).

Se procedió a la conformación de los nichos gingivales con electrobisturí para tener mayor control a la profundidad de corte y para obtener más definidos los ángulos rectos y la superficie plana que se necesitaba sobre los tejidos blandos. Después de la conformación con electrobisturí, se cementó la prótesis provisional, comprobando que la isquemia desapareciera antes de los tres minutos para evitar ocasionar inflamación tisular (Figura 5).

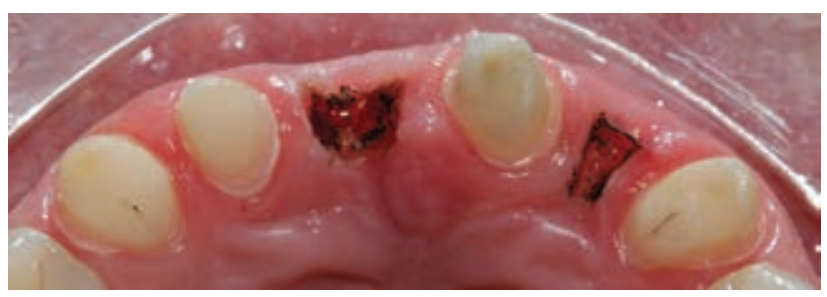

Figura 5: Fotografía oclusal, conformación de nichos con electrobisturí.

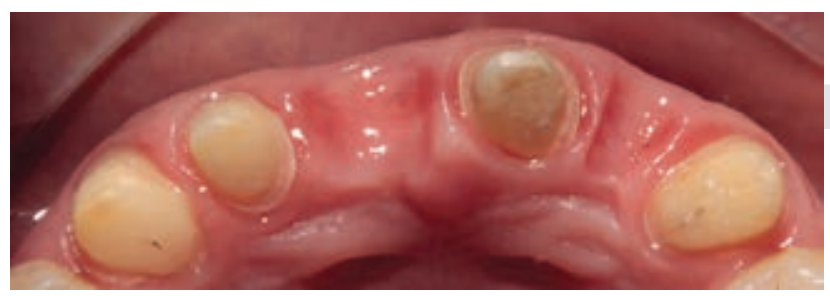

Figura 6: Fotografía oclusal donde se muestran los nichos ya conformados.

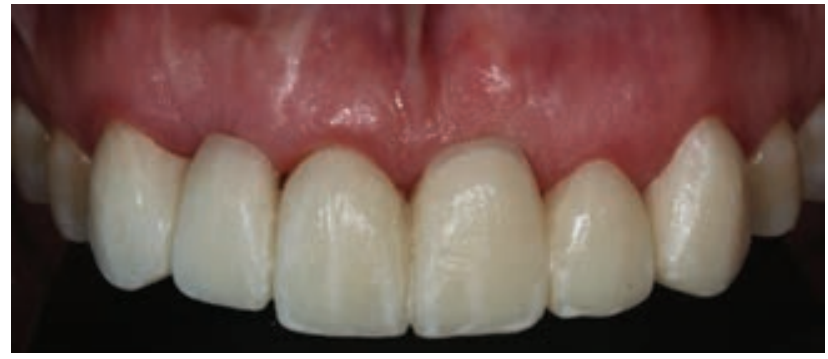

Figura 7: Fotografía con la prótesis provisional colocada en boca.

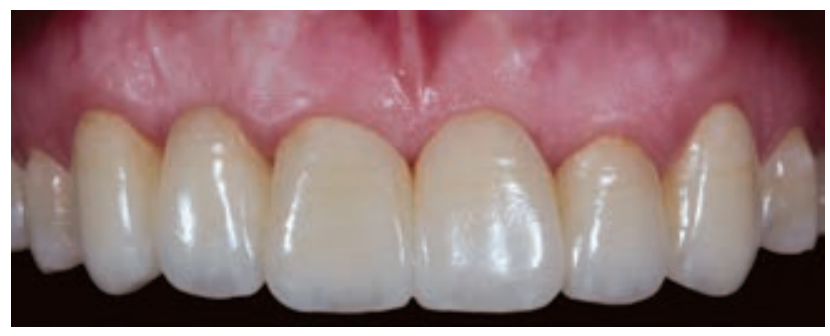

Figura 8: Prótesis definitiva cementada.

Se citó a control a la paciente siete días después de la cementación de provisionales, se observó la migración de papilas hacia las troneras de la prótesis y los nichos gingivales empezaron a conformarse, se modificó el póntico de la prótesis realizando un incremento de resina fluida para generar más presión sobre los tejidos y así obtener mejores resultados. Después de haber modificado los pónticos, es decir, agregando resina fluida dos ocasiones, a los 15 días se obtuvieron los resultados óptimos de los tejidos blandos, la completa formación de la papila, las superficies planas y ángulos rectos deseados en los nichos gingivales (Figuras 6 y 7 ).

Se procedió a la toma de impresión con polivinilsiloxano por adición, se tuvo una amplia comunicación con el laboratorio para la confección de la prótesis definitiva, el material de dicha prótesis fue estructurado por núcleos de zirconio y estratificado con cerámica (Zirkonzahn). Como resultado final, la prótesis definitiva muestra una total integración con el tejido blando, buena estabilidad de color, un adecuado perfil de emergencia por parte de los pónticos y la formación de la papila en su totalidad. Los tejidos se encuentran sanos y en equilibrio con la prótesis definitiva. Se dieron citas de control a la paciente cada mes, después del año de finalizar el tratamiento, se observan los resultados óptimos, se mantienen las mismas condiciones, el tejido totalmente sano (Figura 8). 


\section{DISCUSIÓN}

Debido a las pérdidas dentales prematuras se han propuesto distintas soluciones protésicas, una de ellas son los pónticos. El tipo de póntico E es una excelente opción innovadora para el tratamiento de los rebordes residuales con la finalidad de ofrecer un buen tratamiento, estéticamente aceptable y que además brinda un buen perfil de emergencia. El tratamiento de este caso clínico sobre el reborde alveolar fue planeado con base en lo establecido por Korman; el póntico deberá contar con la forma anatómica de $90^{\circ}$ en los ángulos del póntico en contacto con la encía, para así formar la apariencia de naturalidad en cuanto al perfil de emergencia, brindar soporte a la encía vestibular y crear aparentemente un surco gingival. De acuerdo con los resultados de este caso clínico, se pudo comprobar lo antes mencionado, ya que se respetó el grosor del tejido vestibular y se sumergió el póntico sobre el tejido gingival entre 2 y $3 \mathrm{~mm}^{7}$

\section{CONCLUSIONES}

El póntico E brinda un adecuado perfil de emergencia y una correcta integridad entre la prótesis definitiva y los tejidos blandos. Gracias a la correcta manipulación de los tejidos blandos con la prótesis provisional, a los procedimientos regenerativos de los tejidos con injerto de tejido subepitelial, y al remanente de tejido duro y blando de la paciente, se consiguió un adecuado cierre de la papila interproximal. Se concluye que el póntico E es una buena opción para el tratamiento de rebordes residuales, ofreciendo al paciente óptimos resultados estéticos, funcionales y de la misma manera, le facilita la adecuada higiene.

\section{BIBLIOGRAFÍA}

1. Kois JC. The restorative-periodontal interface: biological parameters. Periodontol 2000. 1996; 11: 29-38.
2. Kois JC. Altering gingival levels. The restorative connection part I: biological variables. J Esthet Dent. 1994; 6 (1): 3-9.

3. Cronin RJ, Wardle WL. Loss of anterior interdental tissue: periodontal and prosthodontic solutions. J Prosthet Dent. 1983; 50: 505-509.

4. Pimentel-Hernández J, Salazar-Urquiza A. Use of zirconia in full maxillary rehabilitation on implants. Clinical case report. Rev Odont Mex. 2015; 19 (1): 43-47.

5. Oh SC, Cha DH, Lee Jl. Combined application of roll flap and combination onlay-interpositional graft to enhance esthetics of maxillary anterior fixed partial denture: A case report. J Adv Prosthodont. 2016; 8 (1): 70-74.

6. Reyes-Moreno G, Ríos-Szalay E. Diseño de póntico ovoide mediante contorno gingival: reporte de dos casos clínicos. Rev Odont Mex. 2011; 15 (4): 257-262.

7. Korman RP. Enhancing esthetics with a fixed prosthesis utilizing an innovative pontic design and periodontal plastic surgery. J Esthet Restor Dent. 2015; 27 (1): 13-28.

8. Seibert JS. Reconstruction of deformed, partially edentulous ridges, using full thickness onlay grafts. Part I. Technique and wound healing. Compend Contin Educ Dent. 1983; 4 (5): 437-453.

9. Castellanos SJL, López PRA, Fandiño TLA. Papila gingival. Aspectos biológicos en la conservación y predicción de su tamaño en la colocación de implantes dentales. Rev Mex Periodontol. 2012; 3 (1): 10-14.

10. Newman MG, Takei HH. Carranza. Periodontología clínica. 9a edición. Editorial Interamericana; 2003. Cap. 2, p. 47.

11. Lister-Blondet CR, Alarcón-Palacios MA. Fenotipos periodontales. Rev Estomatol Herediana. 2010; 20 (4): 227-230.

12. Godoy C, Javer E, Caffarena R, López C. Tridimensional augmentation of an alveolar ridge by means of a modified technique of a grafting of connective interposed and overlapped tissue. Rev Clin Periodoncia Implantol Rehabil Oral. 2008; 1 (1): 27-31.

13. Tarnow DP, Magner AW, Fletcher P. The effect of the distance from the contact point to the crest of bone on the presence or absence of the interproximal dental papilla. J Periodontol. 1992; 63: 995-996.

Correspondencia:

Esp. Trilce Melannie Virgilio Virgilio

Escuela Nacional de Estudios Superiores (ENES)

Unidad León, UNAM.

Blvd. UNAM Núm. 2011

Predio El Saucillo y el Potrero,

Comunidad de los Tepetates, 37684,

León, Guanajuato.

E-mail: trilcemelannie@gmail.com 